\title{
Propionic Academia: Exome Sequencing Identified Novel Mutation in Exon 12 of PCCA Gene
}

\author{
Raziyeh Khalesia ${ }^{\mathrm{a}}$, Masoud Garshasbia, b
}

\begin{abstract}
Propionic acidemia (PA) is a rare autosomal recessive genetic disorder resulting from propionyl-coenzyme A carboxylase deficiency. This mitochondrial enzyme is a heterocopolymer of two subunits a and $b$ that are encoded by PCCA and PCCB genes, respectively. The phenotypes of PCCA mutations are most varied ranging from mild to lethal within a few days after birth because there is great heterogeneity in the mutations of PCCA, while PCCB bears only a limited number of mutations. Deep resequencing of all human genes could potentially identify allelic variants involved in a given rare monogenic disease. Whole exome sequencing (WES) is well justified as an efficient strategy to search for mutations in rare Mendelian disorders. Here, we analyzed an Iranian couple with the history of having a child who died probably due to PA by WES. We could report a novel heterozygous non-sense mutation (p.Y380X) in exon 12 of the PCCA gene, resulting in the protein truncation. We could find that both of parents are carrier for a heterozygous novel non-sense mutation in PCCA gene. We showed that WES in parents, along with appropriate filtering against public SNP databases, is sufficient to identify carriers for a known monogenic disorder, PA, in a consanguineous family.
\end{abstract}

Keywords: Autosomal recessive; Propionic acidemia; Rare disorder

\section{Introduction}

Propionic acidemia (PA, OMIM \#606054) is a rare [1] autosomal recessive genetic disease [2] resulting from propionylcoenzyme A (CoA) carboxylase deficiency [3]. This mitochondrial enzyme is essential near the end of the catabolic pathway to metabolize leucine, isoleucine, valine, threonine, methionine [3-6] and 3-carbon fatty acids [2].

Propionyl-CoA carboxylase catalyzes conversion of prop-

Manuscript accepted for publication January 11, 2017

aDepartment of Medical Genetics, Faculty of Medical Sciences, Tarbiat Modares University, Tehran, Iran

${ }^{b}$ Corresponding Author: Masoud Garshasbi, Department of Medical Genetics, Faculty of Medical Sciences, Tarbiat Modares University, Tehran, Iran.

Email: masoud.garshasbi@modares.ac.ir

doi: https://doi.org/10.14740/jmc2743e
ionyl-CoA to methylmalonyl-CoA [3-6]. The enzyme is a heterocopolymer of two subunits a and $b$ [7] that its configuration is either a4b4 or a6b6 [8]. Then a subunit catalyzes an ATPdependent carbon dioxide in addition to the biotin producing carboxybiotin. Then, carboxy group of the carboxybiotin is transferred to propionyl-CoA generating methylmalonyl-CoA by $b$ subunit $[3,9]$. These subunits are encoded by PCCA and PCCB genes located on chromosomes 13 and 3 [2-6].

The phenotypes of PCCA mutations are most varied ranging from mild to lethal within a few days after birth because there is great heterogeneity in the mutations of PCCA, while PCCB bears only a limited number of mutations $[3,9]$. So, in general, defects in these genes result in insufficiency of the enzyme and accumulation of propionyl-CoA [3-6], ammonia and severe ketoacidosis [2].

Clinical manifestations typically appear when infants wean from breast milk (early-onset) because formula is high in protein, whereas breast milk is relatively low in protein [2]. Most of the affected babies, if not treated, die in the neonatal period or during the first 10 years of life $[10,11]$. In the rare cases, and for unknown reasons, symptoms of this disease occur in adulthood (late-onset) [12]. About $80 \%$ of cases appear during the neonatal period and late-onset cases especially those proving fatal are more uncommon [13].

The most common and most severe form of PA presents in the neonatal period, and patients typically present within their first 3 months of age with acute metabolic acidosis, hyperammonemia and progressive encephalopathy [14], seizures, and coma [1, 2]. Late-onset cases tend to run more heterogeneous courses, presenting with episodic acidosis, acute encephalopathy, mental retardation, and movement disorders, with extrapyramidal signs such as choreoathetosis and dystonia, even without metabolic decompensation $[1,13]$. Early- and late-onset PA can cause severe and permanent neurological damage [15, 16]. The degree of neurological insult is related to the degree of hyperammonemia [15].

Deep resequencing of all human genes could potentially identify allelic variants involved in a given rare monogenic disease [17]. One of approaches is the targeted resequencing of all protein-coding subsequences (whole exome sequencing (WES)), which requires about $5 \%$ as much sequencing as a whole human genome [18-20]. Sequencing of the exome, rather than the entire human genome, is well justified as an efficient strategy to search for mutation discovery of rare Mendelian disorders [21].

Here we analyzed an Iranian couple with the history of 
having a child who died probably due to PA by WES. The child with poor feeding, vomiting, loss of appetite, hypotonia and lethargy born to a first cousin parents died in age of 1 year. Biochemical and enzymatic assays that have been performed for her were in favor of PA diagnosis.

\section{Case Report}

Ten milliliter peripheral bloods were collected from parents in EDTA tubes. Genomic DNA was isolated from leukocytes using salting out standard method. WES was done for one of the parents. Human exonic regions were enriched by using the NimbleGen SeqCap EZ Human Exome Library v2.0 and sequenced on an Illumina HiSeq2000.

Analysis of the WES data was performed by using the alignment and analysis software NextGENe ${ }^{\mathrm{TM}}$ v2.18 by Softgenetics. The raw data were filtered for low quality reads before alignment. Reads that passed the quality filter were aligned to the whole human genome hg18. The average exome coverage was determined using a complete list of human exons generated by the UCSC Table Browser. The same procedure was performed for PCCA gene coverage. The following analytical steps were performed only with reads that matched exonic regions including exon intron-boundaries.

Potential mutations were verified by Sanger sequencing generally using an Applied Biosystems 3130xl instrument. Primer sequences and PCR conditions are available upon request.

By various filtering steps, we focused on the novel variants or those with very MAF less than $1 \%$ found in the genes known so far for methylmalonic academia and PA. We considered the genes for methylmalonic academia as well in order to not miss anything as these two diseases are very similar and it is difficult most of the times to discriminate them based on clinical and biochemical findings. WES revealed only one promising novel heterozygous mutation in PCCA. It included the single-base substitution c. $1140 \mathrm{C}>\mathrm{G}$, resulting in a premature stop codon at amino acid position p.380 (p.Y380X) in exon 12. We could confirm by Sanger sequencing this non-sense mutation in both parents, but we could not confirm the parental segregation of p.Y380X in their infant, in whom no material was available.

\section{Discussion}

More than 7,000 rare diseases have been described, and in the aggregate, these affect more than 25 million people. The majority of these diseases are considered genetic disorders, and many of them are thought to be monogenic. Exome sequencing of a small number of affected family members or affected unrelated individuals is a powerful, efficient and cost-effective strategy for markedly reducing the pool of candidate genes for rare monogenic disorders and may even identify the responsible gene(s) specifically [17]. It uses DNA-enrichment methods and massively parallel nucleotide sequencing to comprehensively identify and type protein-coding variants to identify single nucleotide variants (SNVs), and small insertion/deletions
(49 new) throughout the genome $[22,23]$. This approach is likely to become a standard tool for the discovery of genes underlying rare monogenic diseases [17] because it has been used so far successfully in many rare diseases $[22,23]$.

In this study, we encounter parents with consanguineous marriage that lost their infant because of suffering a genetic disease suspicious to PA. We did not have any material for examination and diagnosis of her disease.

Iran is one of the countries located in the consanguineous marriage belt, where prevalence rate of consanguineous marriages is estimated to be $23-78 \%$ [24]. Therefore, the rate of recessive mutations is expected to be higher in Iranian population compared to other populations [25]. In the country with lower rate of consanguineous marriage, individuals suffering from PA are most commonly compound heterozygotes [26]. As PA is an autosomal recessive disorder [2] and parents were first cousin, we assumed that it is more likely parents are carriers of the same disease-causing variants. So we applied WES on one of the parents and confirmed the variants found in the other parent by Sanger sequencing in order to reduce the cost.

A novel heterozygous non-sense mutation (p.Y380X) in exon 12 of the PCCA gene resulting in the protein truncation was found through this study.

Determining genetic diagnosis prenatally allows patients to make informed reproductive decisions and to be counseled about possible fetal outcomes, management options and recurrence risks. Therefore, it is important for the physician to be conscious of the full spectrum of genetic conditions, and to use appropriate testing and referrals to genetic healthcare providers in order to obtain a specific diagnosis [27].

\section{Conclusions}

We showed that WES in parents, along with appropriate filtering against public SNP databases, is sufficient to identify carriers for a known monogenic disorder, PA, in a consanguineous family. Therefore, principled methods combining genomic, biochemical, and clinical data will be required to usher NGS into the clinical arena [28].

\section{Acknowledgments}

We thank the family for their irreplaceable contribution to this study.

\section{Conflicts of Interest}

I certify that there are no actual or potential conflicts of interest in relation to this article.

\section{References}

1. Sass JO, Hofmann M, Skladal D, Mayatepek E, Schwahn B, Sperl W. Propionic acidemia revisited: a workshop re- 
port. Clin Pediatr (Phila). 2004;43(9):837-843.

2. Baum VC, O'Flaherty JE. Anesthesia for genetic, metabolic, and dysmorphic syndromes of childhood. Lippincott Williams \& Wilkins. 2007.

3. Perez B, Desviat LR, Rodriguez-Pombo P, Clavero S, Navarrete R, Perez-Cerda C, Ugarte M. Propionic acidemia: identification of twenty-four novel mutations in Europe and North America. Mol Genet Metab. 2003;78(1):59-67.

4. Perez-Cerda C, Merinero B, Rodriguez-Pombo P, Perez B, Desviat LR, Muro S, Richard E, et al. Potential relationship between genotype and clinical outcome in propionic acidaemia patients. Eur J Hum Genet. 2000;8(3):187194.

5. Lehnert W, Sperl W, Suormala T, Baumgartner ER. Propionic acidaemia: clinical, biochemical and therapeutic aspects. Experience in 30 patients. Eur J Pediatr. 1994;153(7 Suppl 1):S68-80.

6. van der Meer SB, Poggi F, Spada M, Bonnefont JP, Ogier H, Hubert P, Depondt E, et al. Clinical outcome and longterm management of 17 patients with propionic acidaemia. Eur J Pediatr. 1996;155(3):205-210.

7. Lamhonwah A-M, Barankiewicz TJ, Willard HF, Mahuran DJ, Quan F, Gravel RA. Isolation of cDNA clones coding for the alpha and beta chains of human propionyl-CoA carboxylase: chromosomal assignments and DNA polymorphisms associated with PCCA and PCCB genes. Proceedings of the National Academy of Sciences. 1986;83(13):4864-4868.

8. Campeau E, Dupuis L, Leon-Del-Rio A, Gravel R. Coding sequence mutations in the alpha subunit of propionylCoA carboxylase in patients with propionic acidemia. Mol Genet Metab. 1999;67(1):11-22.

9. Ugarte M, Perez-Cerda C, Rodriguez-Pombo P, Desviat LR, Perez B, Richard E, Muro S, et al. Overview of mutations in the PCCA and PCCB genes causing propionic acidemia. Hum Mutat. 1999;14(4):275-282.

10. Leonard JV, Daish P, Naughten ER, Bartlett K. The management and long term outcome of organic acidaemias. J Inherit Metab Dis. 1984;7(Suppl 1):13-17.

11. Surtees RA, Matthews EE, Leonard JV. Neurologic outcome of propionic acidemia. Pediatr Neurol. 1992;8(5):333-337.

12. Feliz B, Witt DR, Harris BT. Propionic acidemia: a neuropathology case report and review of prior cases. Arch Pathol Lab Med. 2003;127(8):e325-328.

13. Lucke T, Perez-Cerda C, Baumgartner M, Fowler B, Sander S, Sasse M, Scholl S, et al. Propionic acidemia: unusual course with late onset and fatal outcome. Metabolism. 2004;53(6):809-810.

14. Johnson JA, Le KL, Palacios E. Propionic acidemia: case report and review of neurologic sequelae. Pediatr Neurol. 2009;40(4):317-320.

15. Ali M A-A, AbdulKarim S A-M. Atypical presentations of propionic acidemia. Health. 2012;2012.

16. Desviat LR, Perez B, Perez-Cerda C, Rodriguez-Pombo P, Clavero S, Ugarte M. Propionic acidemia: mutation update and functional and structural effects of the variant alleles. Mol Genet Metab. 2004;83(1-2):28-37.

17. Ng SB, Buckingham KJ, Lee C, Bigham AW, Tabor HK, Dent KM, Huff CD, et al. Exome sequencing identifies the cause of a mendelian disorder. Nat Genet. 2010;42(1):3035.

18. Ng SB, Turner EH, Robertson PD, Flygare SD, Bigham AW, Lee C, Shaffer T, et al. Targeted capture and massively parallel sequencing of 12 human exomes. Nature. 2009;461(7261):272-276.

19. Choi M, Scholl UI, Ji W, Liu T, Tikhonova IR, Zumbo P, Nayir A, et al. Genetic diagnosis by whole exome capture and massively parallel DNA sequencing. Proc Natl Acad Sci U S A. 2009;106(45):19096-19101.

20. Hodges E, Xuan Z, Balija V, Kramer M, Molla MN, Smith SW, Middle CM, et al. Genome-wide in situ exon capture for selective resequencing. Nat Genet. 2007;39(12):15221527.

21. Stenson PD, Mort M, Ball EV, Howells K, Phillips AD, Thomas NS, Cooper DN. The Human Gene Mutation Database: 2008 update. Genome Med. 2009;1(1):13.

22. Singleton AB. Exome sequencing: a transformative technology. Lancet Neurol. 2011;10(10):942-946.

23. Fan HC, Gu W, Wang J, Blumenfeld YJ, El-Sayed YY, Quake SR. Non-invasive prenatal measurement of the fetal genome. Nature. 2012;487(7407):320-324.

24. Jalal Abbasi-Shavazi M, McDonald P, Hosseini-Chavoshi M. Modernization or cultural maintenance: the practice of consanguineous marriage in Iran. J Biosoc Sci. 2008;40(6):911-933.

25. Rubio-Cabezas O, Patch AM, Minton JA, Flanagan SE, Edghill EL, Hussain K, Balafrej A, et al. Wolcott-Rallison syndrome is the most common genetic cause of permanent neonatal diabetes in consanguineous families. J Clin Endocrinol Metab. 2009;94(11):4162-4170.

26. Pena L, Franks J, Chapman KA, Gropman A, Ah Mew N, Chakrapani A, Island E, et al. Natural history of propionic acidemia. Mol Genet Metab. 2012;105(1):5-9.

27. Babkina N, Graham Jr JM. New genetic testing in prenatal diagnosis. Elsevier. 2013.

28. Knies K, Schuster B, Ameziane N, Rooimans M, Bettecken $\mathrm{T}$, de Winter J, Schindler D. Genotyping of fanconi anemia patients by whole exome sequencing: advantages and challenges. PLoS One. 2012;7(12):e52648. 